Revista Destaques Acadêmicos, Lajeado, v. 9, n. 2, 2017. ISSN 2176-3070 DOI: http://dx.doi.org/10.22410/issn.2176-3070.v9i2a2017.1306 www.univates.br/revistas

\title{
OS BENEFÍCIOS DE PRESTAÇÃO CONTINUADA À LUZ DOS PRINCÍPIOS DA SEGURIDADE SOCIAL NA CONCRETIZAÇÃO DO ESTADO SOCIAL E DEMOCRÁTICO DE DIREITO
}

\author{
Ana Cristine Majolo ${ }^{1}$, Fernanda Pinheiro Brod ${ }^{2}$
}

\begin{abstract}
Resumo: Este artigo possui como tema a interpretação dos princípios constitucionais frente ao critério econômico utilizado para deferimento do benefício de prestação continuada. Num primeiro momento há análise dos princípios da solidariedade, do não retrocesso e da dignidade humana, buscando identificar suas características e aplicabilidade. Em continuidade, discorre-se acerca do Estado Democrático de Direito e os limites da Reforma Constitucional. Por último, discute-se sobre a evolução jurisprudencial dos benefícios de prestação continuada frente ao modelo de estado adotado pela Constituição Federal de 1988.
\end{abstract}

Palavras-chave: Seguridade social. Princípios constitucionais. Benefício de prestação continuada. Estado Democrático de Direito.

\section{INTRODUÇÃO}

A legislação infraconstitucional, seguindo uma proposta constitucional, garante um salário mínimo de benefício mensal às pessoas portadoras de deficiência e aos idosos sem condições mínimas à própria manutenção, quando comprovado critérios objetivos, dentre eles idade e renda mensal do grupo familiar.

No entanto, a norma que possibilita a concessão de tal benefício é incompatível com o fenômeno social contemporâneo, onde as desigualdades se apresentam de forma maximizadas, sendo imprescindível reinterpretar os critérios necessários à concessão do benefício, a fim de não afrontar a dignidade humana das pessoas mais necessitadas.

1 Bacharela em Direito pelo Centro Universitário UNIVATES, de Lajeado/RS.

2 Professora do Centro Universitário UNIVATES, Lajeado/RS. Doutora em Direito pela Pontifícia Universidade Católica do Rio Grande do Sul, PUC, Brasil. 
Diante dessa realidade fática os magistrados encontram-se frente a um confronto entre a norma legal e o princípio constitucional, cabendo ao operador jurídico ponderar e solucionar cada caso concreto da melhor forma possível.

\section{PROCEDIMENTOS METODOLÓGICOS}

Inicialmente, com relação ao método de pesquisa utilizado, optou-se pelo método dedutivo, o qual possui como característica partir de argumentos gerais para chegar a conclusões particulares. Num primeiro momento haverá a identificação dos princípios da Seguridade Social após, a demonstração dos requisitos legais inerentes à concessão do benefício de prestação continuada e por último, a discussão da aplicação dos princípios constitucionais na concessão do benefício assistencial.

A pesquisa produzida, quanto à abordagem será qualitativa e quanto aos procedimentos técnicos, o artigo científico utiliza-se da técnica bibliográfica e documental, sendo a primeira desenvolvida com base em obras de divulgação diversas e a segunda com base na legislação vigente.

\section{PRINCÍPIOS DA SEGURIDADE SOCIAL}

AConstituição Federal de 1988, preocupada com a parcela hipossuficiente da população, elencou no artigo 203 os objetivos dessa assistência, quais sejam a proteção à família, à maternidade, à infância, à adolescência e a velhice; o amparo às crianças e adolescentes carentes; a promoção da integração ao mercado de trabalho; a habilitação e reabilitação das pessoas portadoras de deficiência e a promoção de sua integração à vida comunitária; a garantia de um salário mínimo de benefício mensal à pessoa portadora de deficiência e ao idoso que comprovem não possuir meios de prover a própria manutenção ou de tê-la provida por sua família, conforme dispuser a lei.

Para uma análise fidedigna, baseada nos preceitos constitucionais, é importante refletir acerca de alguns princípios norteadores do direito previdenciário, que são aplicados a assistência social. O presente trabalho irá se ater a três deles, os quais foram escolhidas em vista de sua frequente utilização na jurisprudência.

O primeiro é o princípio da solidariedade, o qual, na intenção de englobar toda a coletividade, prevê que todos aqueles que possuem capacidade contributiva, devem contribuir também àqueles que não possuem condições financeiras de arcar com o custeio da Previdência Social. O doutrinador Correia refere que:

Trata-se de princípio constitucional explícito (arts. 3o, I, e 195, caput, da Constituição Federal). Embora vislumbrado sempre sob a lógica do custeio, deve ser tratado também para fins da concessão com justiça social dos benefícios. Caso contrário, bastaria solidariedade 
no custeio, pouco importando esta no instante da distribuição dos benefícios, o que romperia o pacto de fidúcia que deve informar, como elemento constitutivo, qualquer ato jurídico de seguridade social (CORREIA, 2013, p. 114).

Nas palavras de Balera e Mussi (2015) o princípio da solidariedade exige uma participação obrigatória de toda sociedade, a qual, mediante o recolhimento de contribuições sociais e tributos, garante que a geração de hoje esteja amparada.

Nesta senda, há de se compreender que a lógica do Seguro Social difere em muito da do seguro privado, pois a obrigação de contribuir naquele não resulta, obrigatoriamente, em uma contrapartida pessoal. Trata-se em suma, de um sistema protetivo:

A solidariedade está na base dos regimes de financiamento da previdência social na modalidade repartição simples, pois as cotizações individuais formarão uma poupança coletiva ao dispor de todos. Se assim não fosse, caso as contribuições se destinassem a fundos individuais, como nos regimes de capitalização, o beneficiário ficaria ao sabor da sorte no curto e médio prazos, já que seus aportes seriam insuficientes para garantir seu sustento em face de contingências que o impedissem de trabalhar. Por isso, em que pese o crescimento de sistemas de previdência complementar, assentados de forma individual, é imprescindível a manutenção da previdência pública básica, de caráter solidário (HUBACK, 2012, p. 7).

O segundo princípio que será discutido neste artigo é o princípio do não retrocesso. Este princípio, jovem no cenário jurídico, surgiu da necessidade de frear os constantes ataques à Constituição Federal, que se iniciaram na década de 90, por intermédio de medidas provisórias e emendas constitucionais (FERREIRA, 2015).

Importante ressaltar que o debate acerca deste princípio iniciou-se na década de 90, quando, quando começaram a serem propostas inúmeras emendas constitucionais, as quais afrontavam diretamente os direitos sociais garantidos na Carta Magna. Neste cenário, com o objetivo de dar efetividade aos direitos sociais elencados na Constituição, surge o princípio do não retrocesso, que nas palavras de Canotilho (2003, p. 338-339):

[...] quer dizer-se que os direitos sociais e econômicos (ex.: direito dos trabalhadores, direito à assistência, direito à educação), uma vez obtido um determinado grau de realização, passam a constituir, simultaneamente, uma garantia institucional e um direito subjetivo. A 'proibição de retrocesso social' nada pode fazer contra as recessões e crises econômicas (reversibilidade fática), mas o princípio 
em análise limita a reversibilidade dos direitos adquiridos (ex.: segurança social, subsídio de desemprego, prestações de saúde), em clara violação do princípio da proteção da confiança e da segurança dos cidadãos no âmbito económico, social e cultural, e do núcleo essencial da existência mínima inerente ao respeito pela dignidade da pessoa humana.

Verifica-se que a aplicação do princípio do não retrocesso tem o objetivo de que o legislador, ao criar novas normas, não possa se abster na essência da Constituição, impedindo a violação de preceitos existentes, tais como garantias sociais:

Com isso, firma-se a vedação do legislador em reduzir qualquer direito social assegurado constitucionalmente, sob pena de violação do princípio de proteção da confiança e segurança dos cidadãos no âmbito social, e de inconstitucionalidade. A partir da necessidade de tutela dos direitos sociais, principalmente no que se refere à dignidade da pessoa humana, a assistência social trouxe um auxílio aos portadores de deficiência que não conseguissem prover seu sustento, ou tê-lo provido por sua família. Assim, a ação efetiva de vedação de retrocesso social, em se tratando de garantir uma vida digna às pessoas portadoras de deficiência, passou a ser concretizada a partir da previsão constitucional de concessão do benefício assistencial de prestação continuada (MACIEL, 2008, texto digital).

Podemos considerá-lo, portanto, como um direito constitucional de resistência, o qual possui o intuito de evitar que garantias constitucionais, tais como os benefícios sociais, sejam revertidas em prejuízo da sociedade.

Por último, mas não menos importante, cabe referência há um dos princípios mais utilizados para garantir os direitos fundamentais dispostos na Constituição de 1988. Trata-se do princípio da dignidade humana, o qual, nas palavras de Sarlet (2012, p. 146-147), possui "dupla função":

[...] o princípio da dignidade da pessoa humana cumpre, ao menos na perspectiva ora versada dupla função. Com efeito, sendo também parte - ainda que variável - integrante do conteúdo dos direitos fundamentais (ao menos, em regra), e para além da discussão em torno de sua identificação com o núcleo essencial, constata-se que o princípio da dignidade da pessoa humana serve como importante elemento de proteção dos direitos contra medidas restritivas. [...] Todavia, cumpre relembrar que o princípio da dignidade da pessoa humana também serve como justificativa para a imposição de restrições a direitos fundamentais [...]. O quem importa, no momento, é que sempre se poderá afirmar, como já anunciado no título deste segmento, que a dignidade da pessoa atua simultaneamente como limite dos direitos e limite dos limites, isto é, barreira contra a 
atividade restritiva dos direitos fundamentais, o que efetivamente não afasta a controvérsia sobre o próprio conteúdo da dignidade e a existência, ou não, de uma violação do seu âmbito de proteção.

Importante referir que a dignidade humana é princípio fundamental previsto na Constituição Federal de 1988, como bem descreve o art. $1^{\circ}$, inc. III:

Art. $1^{\circ}$. A República Federativa do Brasil, formada pela união indissolúvel dos Estados e Municípios e Distrito Federal, constituise em Estado Democrático de Direito e tem como fundamentos:

$[\ldots]$

II - a dignidade da pessoa humana (BRASIL, 1988, texto digital).

Para Lima (2002), o princípio tem a função de guiar o legislador e o intérprete das leis, a fim de que eles apliquem a legislação vigente da melhor maneira às novas situações jurídicas, as quais surgem de formas diferentes todos os dias.

Nas palavras de Cunha (2012, texto digital):

A dignidade é qualidade inerente à condição humana. O ordenamento jurídico que adota a dignidade humana como princípio norteador, veda a coisificação e a instrumentalização do ser humano. O Direito não decreta a dignidade humana, posto que essa seja atributo inerente da vida humana; a sua recepção na condição de princípio constitucional faz apenas o seu reconhecimento, com a imantação de direitos fundamentais destinados a amparar a garantia da existência digna.

Nesse contexto, deve-se considerar a maneira como os seres humanos se caracterizam, referindo quais são os fatores que tornam uma pessoa igual à outra, e por consequência digna de ser:

O que a exigência de igualdade de reconhecimento implica é que quando despimos uma pessoa de todas as suas características contingentes e acidentais resta sob isso uma qualidade humana essencial que é merecedora de certo nível mínimo de respeito [...]. A cor da pele, a aparência, a classe social e a fortuna, o gênero, a bagagem cultural e até os talentos naturais de uma pessoa são todos acidentes de nascimento relegados à classe de características não essenciais. Tomamos decisões sobre quem desejamos ter por amigos, com quem desejamos nos casar, ou fazer negócios, ou quem queremos evitar em ocasiões sociais com base nestas características secundárias. Na esfera política, porém, exige-se que respeitemos as pessoas igualmente com base no Fator $\mathrm{X}$ que possuem. Podemos cozinhar, comer, torturar, escravizar ou derreter a carcaça de qualquer criatura que careça do Fator $X$, mas se fizermos o mesmo 
com um ser humano, somos culpados de um 'crime contra a humanidade'. Atribuímos a seres com o Fator X não apenas direito humanos como, se forem adultos, direitos políticos também - isto é, o direito de viver em comunidades políticas democráticas onde seus direitos à expressão, religião, associação e à participação política são respeitados (FUKUYAMA, 2003, p. 158-159).

Entende-se, por fim, que se o texto constitucional estabelece que a dignidade da pessoa humana seja princípio fundamental, este preceito deve ser respeitado, pois se trata de um princípio de suma importância, norteador de diversas interpretações e decisões judiciais.

\section{O ESTADO DEMOCRÁTICO DE DIREITO E OS LIMITES DA REFORMA CONSTITUCIONAL}

Inicialmente mostra-se importante falar sobre o conceito de Estado Democrático de Direito, a fim de compreender as nuances deste sistema institucional. Este, nas palavras de Streck e Morais (2006, p. 97-98):

O Estado Democrático de Direito tem um conteúdo transformador da realidade, não se restringindo como Estado Social de Direito, a uma adaptação melhorada das condições sociais de existência. Assim o seu conteúdo ultrapassa o aspecto material de concretização de uma vida digna ao homem e passa a agir simbolicamente como fomentador da participação pública no processo de construção e reconstrução de um projeto de sociedade, apropriando-se do caráter incerto da democracia para veicular uma perspectiva de futuro voltada à produção de uma nova sociedade, onde a questão da democracia contém e implica, necessariamente, a solução do problema das condições materiais de existência.

Assim é possível dizer que no Estado Democrático de Direito a vontade da sociedade é representada por intermédio das leis, as quais são criadas em face de demanda da população. O desenvolvimento da sociedade está intimamente atrelado a tais inovações legislativas, as quais, cada vez mais, procuram reafirmar direitos e garantias fundamentais previstos na Constituição de 1988.

Nas palavras de Barroso (2014, p. 113-114), a Constituição no Estado Democrático de Direito tem duas funções principais:

Em primeiro lugar, compete a ela veicular consensos mínimos, essenciais para a dignidade das pessoas e para o funcionamento do regime democrático, e que não devem poder ser afetados por maiorias políticas ocasionais. Esses consensos elementares, embora possam variar em função das circunstâncias políticas, sociais e históricas de cada país, envolvem a garantia de direitos 
fundamentais, a separação e a organização dos Poderes constituídos e a fixação de determinados fins de natureza política ou valorativa. Em segundo lugar, cabe à Constituição garantir o espaço próprio do pluralismo político, assegurando o funcionamento adequado dos mecanismos democráticos. A participação popular, os meios de comunicação social, a opinião pública, as demandas dos grupos de pressão e dos movimentos sociais imprimem à política e à legislação uma dinâmica própria e exigem representatividade e legitimidade corrente do poder. Há um conjunto de decisões que não podem ser subtraídas dos órgãos eleitos pelo povo a cada momento histórico. A Constituição não pode, não deve nem tem a pretensão de suprimir a deliberação legislativa majoritária.

Após breve análise acerca do Estado Democrático de Direito, adotado pelo Brasil, existe outro ponto chave que merece ser discutido. Trata-se dos limites da reforma constitucional.

O atual cenário brasileiro é de crise econômica e política, resultado de anos de negligência por parte dos governantes, o resultou na imposição de medidas mais severas à população, a fim de conter o avanço da crise econômico.

Neste ponto, importante salientar que o discurso veiculado pelo governo é de que a sociedade brasileira, para se ver livre da crise, terá necessariamente de passar por um período de recessão. As medidas que estão sendo propostas, no entanto, são questionáveis, pois afetam, em sua grande maioria, a fração menos favorecida de cidadãos brasileiros.

No entanto, existe um limite de reforma constitucional que impede a segregação de direitos adquiridos e elencados na Carta Magna. Sarlet, Marinoni e Mitidiero (2015, p. 121-122) lecionam:

A Constituição Federal de 1988, por sua vez, pode ser considerada, pelo menos no contexto da evolução brasileira, a que instituiu um leque de limites mais amplo e exigente, especialmente no plano dos assim chamados limites materiais (convencionalmente designados de 'cláusulas pétreas') existem os limites de ordem formal (de caráter precipuamente procedimental), bem como os limites circunstanciais e os chamados limites temporais.

Verifica-se, portanto, que em que pese reformas legislativas estejam sendo propostas, não podem elas violar direitos e garantias previstos na Constituição Brasileira vigente. 
Como exemplo das medidas que vêm sendo impostas atualmente, tem-se o Projeto de Emenda Constitucional 287/201633, o qual prevê inúmeras mudanças no cenário previdenciário tais como o aumento da idade mínima para aposentadorias por tempo de contribuição, por idade e rural.

A discussão da norma proposta enseja, até sua aprovação, questionamentos acerca de possíveis violações constitucionais.

Neste ponto, os princípios da dignidade humana, do não retrocesso e da solidariedade, debatidos anteriormente, são de suma importância, pois impossibilitam a supressão de direitos e garantias fundamentais existentes na Constituição.

\section{A APLICABILIDADE DOS PRINCÍPIOS CONSTITUCIONAIS E A CONCRETIZAÇÃO DO ESTADO DEMOCRÁTICO DE DIREITO NA ANÁLISE DA CONCESSÃO DO BENEFÍCIO ASSISTENCIAL DE PRESTAÇÃO CONTINUADA E SUA EVOLUÇÃO JURISPRUDENCIAL}

O cenário jurídico modificou-se de forma considerável nos últimos anos, especialmente após o advento da Constituição Federal de 1988, pois, além de conter um capítulo específico aos direitos fundamentais, previu, de igual forma, um capítulo à Seguridade Social. Assim, o Estado Democrático de Direito é fundamentado na dignidade humana, razão pela qual o fundamento republicano deve orientar as políticas públicas, a sociedade e as atividades jurídicas.

O inciso V do artigo 203 da Constituição Federal dispõe especificamente acerca da Assistência Social:

Art. 203. A assistência social será prestada a quem dela necessitar, independentemente de contribuição à seguridade social, e tem por objetivos:

[...]

V - a garantia de um salário mínimo de benefício mensal a pessoa portadora de deficiência e ao idoso que comprove não possuir meios de prover à própria manutenção ou de tê-la provida por sua família, conforme dispusera a lei (BRASIL, 1988, texto digital).

A regulamentação do benefício previsto no texto constitucional encontrase no artigo 20 e seguintes da Lei 8.742/93, que dispõe, em seu parágrafo terceiro, o critério econômico para deferimento do benefício, qual seja renda

3 Atualmente a Proposta de Emenda Constitucional tramita na Câmara e aguarda parecer de comissão especial designada. BRASIL. Câmara dos Deputados. Projetos de Lei e Outras Proposições: PEC 287/2016. Disponível em: <http:/ / www.camara.gov.br/proposicoesWeb/ fichadetramitacao?idProposicao=2119881>. Acesso em: 25 fev. 2017. 
mensal per capita inferior a 1/4 (um quarto) do salário-mínimo, eis o teor da norma:

Art. 20. O benefício de prestação continuada é a garantia de um salário-mínimo mensal à pessoa com deficiência e ao idoso com 65 (sessenta e cinco) anos ou mais que comprovem não possuir meios de prover a própria manutenção nem de tê-la provida por sua família.

[...]

$\S 3^{\circ}$ Considera-se incapaz de prover a manutenção da pessoa com deficiência ou idosa a família cuja renda mensal per capita seja inferior a 1/4 (um quarto) do salário-mínimo (BRASIL, 1993, texto digital).

O Supremo Tribunal Federal, questionado sobre a constitucionalidade do critério econômico, reconheceu que este se encontra defasado, haja vista que a economia brasileira se transformou substancialmente após a promulgação da Constituição de 1988.

Benefício assistencial de prestação continuada ao idoso e ao deficiente. Art. 203, V, da Constituição. A Lei de Organização da Assistência Social (LOAS), ao regulamentar o art. 203, V, da Constituição da República, estabeleceu critérios para que o benefício mensal de um salário mínimo fosse concedido aos portadores de deficiência e aos idosos que comprovassem não possuir meios de prover a própria manutenção ou de tê-la provida por sua família. 2. Art. 20, § $3^{\circ}$ da Lei 8.742/1993 e a declaração de constitucionalidade da norma pelo Supremo Tribunal Federal na ADI 1.232. Dispõe o art. 20, § $3^{\circ}$, da Lei 8.742/93 que "considera-se incapaz de prover a manutenção da pessoa portadora de deficiência ou idosa a família cuja renda mensal per capita seja inferior a $1 / 4$ (um quarto) do salário mínimo". O requisito financeiro estabelecido pela lei teve sua constitucionalidade contestada, ao fundamento de que permitiria que situações de patente miserabilidade social fossem consideradas fora do alcance do benefício assistencial previsto constitucionalmente. Ao apreciar a Ação Direta de Inconstitucionalidade 1.232-1/DF, o Supremo Tribunal Federal declarou a constitucionalidade do art. 20, $\S 3^{\circ}$, da LOAS. 3. Reclamação como instrumento de (re)interpretação da decisão proferida em controle de constitucionalidade abstrato. Preliminarmente, arguido o prejuízo da reclamação, em virtude do prévio julgamento dos recursos extraordinários 580.963 e 567.985, o Tribunal, por maioria de votos, conheceu da reclamação. O STF, no exercício da competência geral de fiscalizar a compatibilidade formal e material de qualquer ato normativo com a Constituição, pode declarar a inconstitucionalidade, incidentalmente, de normas tidas como fundamento da decisão ou do ato que é impugnado na reclamação. Isso decorre da própria competência atribuída ao STF 
para exercer o denominado controle difuso da constitucionalidade das leis e dos atos normativos. A oportunidade de reapreciação das decisões tomadas em sede de controle abstrato de normas tende a surgir com mais naturalidade e de forma mais recorrente no âmbito das reclamações. É no juízo hermenêutico típico da reclamação - no 'balançar de olhos' entre objeto e parâmetro da reclamação - que surgirá com maior nitidez a oportunidade para evolução interpretativa no controle de constitucionalidade. Com base na alegação de afronta a determinada decisão do STF, o Tribunal poderá reapreciar e redefinir o conteúdo e o alcance de sua própria decisão. E, inclusive, poderá ir além, superando total ou parcialmente a decisão-parâmetro da reclamação, se entender que, em virtude de evolução hermenêutica, tal decisão não se coaduna mais com a interpretação atual da Constituição. 4. Decisões judiciais contrárias aos critérios objetivos preestabelecidos e Processo de inconstitucionalização dos critérios definidos pela Lei 8.742/1993. A decisão do Supremo Tribunal Federal, entretanto, não pôs termo à controvérsia quanto à aplicação em concreto do critério da renda familiar per capita estabelecido pela LOAS. Como a lei permaneceu inalterada, elaboraram-se maneiras de contornar o critério objetivo e único estipulado pela LOAS e avaliar o real estado de miserabilidade social das famílias com entes idosos ou deficientes. Paralelamente, foram editadas leis que estabeleceram critérios mais elásticos para concessão de outros benefícios assistenciais, tais como: a Lei 10.836/2004, quecriou oBolsa Família; a Lei10.689/2003, queinstituiu o Programa Nacional de Acesso à Alimentação; a Lei 10.219/01, que criou o Bolsa Escola; a Lei 9.533/97, que autoriza o Poder Executivo a conceder apoio financeiro a municípios que instituírem programas de garantia de renda mínima associados a ações socioeducativas. O Supremo Tribunal Federal, em decisões monocráticas, passou a rever anteriores posicionamentos acerca da intransponibilidade dos critérios objetivos. Verificou-se a ocorrência do processo de inconstitucionalização decorrente de notórias mudanças fáticas (políticas, econômicas e sociais) e jurídicas (sucessivas modificações legislativas dos patamares econômicos utilizados como critérios de concessão de outros benefícios assistenciais por parte do Estado brasileiro). 5. Declaração de inconstitucionalidade parcial, sem pronúncia de nulidade, do art. 20, § 3º da Lei 8.742/1993. 6. Reclamação constitucional julgada improcedente (Reclamação $n^{\circ}$ 4374, Supremo Tribunal Federal. Tribunal Pleno, Relator: Min. Gilmar Mendes. Julgado em 18/04/2013, publicado em 04/09/2013) (BRASIL, 2013, texto digital).

Atualmente, a orientação do Superior Tribunal de Justiça dá conta de que o magistrado não necessita estar vinculado a um sistema de tarifação legal de provas para delimitar a condição de miserabilidade do requerente. Assim, a condição de miserabilidade não está condicionada a uma renda mensal inferior a 1/4 (um quarto) do salário mínimo per capita. Em precedente proferido 
em julgamento de recurso especial, o Egrégio Tribunal posiciona-se sobre a questão:

RECURSO ESPECIAL REPETITIVO. ART. 105, III, ALÍNEA C DA CF. DIREITO PREVIDENCIÁRIO. BENEFÍCIO ASSISTENCIAL. POSSIBILIDADE DE DEMONSTRAÇÃO DA CONDIÇÃO DE MISERABILIDADE DO BENEFICIÁRIO POR OUTROS MEIOS DE PROVA, QUANDO A RENDA PER CAPITA DO NÚCLEO FAMILIAR FOR SUPERIOR A $1 / 4$ DO SALÁRIO MÍNIMO. RECURSO ESPECIAL PROVIDO (CASTRO; LAZZARI, 2014. p. 853).

[...]

6. Além disso, em âmbito judicial vige o princípio do livre convencimento motivado do Juiz (art. 131 do CPC) e não o sistema de tarifação legal de provas, motivo pelo qual essa delimitação do valor da renda familiar per capita não deve ser tida como único meio de prova da condição de miserabilidade do beneficiado. De fato, não se pode admitir a vinculação do Magistrado a determinado elemento probatório, sob pena de cercear o seu direito de julgar (BRASIL, 2009, texto digital).

Com efeito, o critério econômico, em que pesem os seguidos aumentos do salário mínimo, examinado de forma isolada, diante do cenário socioeconômico atual, apresenta-se como falho perante (i) a técnica legislativa necessária e, principalmente, (ii) ao fundamento republicano baseado nos princípios constitucionais da dignidade humana e da solidariedade.

O ordenamento jurídico positivo deve ser compreendido a partir da visão constitucionalista contemporânea. A Declaração Universal de 1948, o grande documento do século $\mathrm{XX}$, foi fundamento à reaproximação do direito à ética, pois simbolizou a força normativa dos princípios, especialmente o da dignidade humana, que de igual maneira fortaleceu o reencontro do sistema jurídico com o pensamento de Kant, alicerçado no ideal da moral objetiva, paz perpétua e dignidade (CARDOSO, 2010):

[...] Nessa linha, a dignidade da pessoa humana consiste que cada indivíduo é um fim em si mesmo, com autonomia para se comportar de acordo com seu arbítrio, nunca um meio de instrumento para consecução de resultados, não possuindo preço. Consequentemente, o ser humano tem o direito de ser respeitado pelos demais e também reciprocamente respeitá-los (RAMOS, 2014, p. 74).

Assim, a dignidade humana incide sobre as qualidades singulares de cada ser humano, protegendo-o de todo e qualquer tratamento discriminatório. Tal princípio assegura a toda pessoa condições materiais mínimas de sobrevivência, as quais, diante do avanço socioeconômico já citado, modificam- 
se constantemente. Verifica-se, portanto, que o princípio da dignidade humana encontra-se em constante evolução.

Importante referir que a proteção da dignidade humana é dever do Estado, no âmbito de sua limitação da ação estatal, caracterizando o dever de respeito. Dito isso se constata que tal dever encontra-se presente na promoção da dignidade humana na sociedade, por meio da criação e aplicação de políticas públicas eficazes, as quais resultam no fornecimento de condições materiais mínimas ideais à sobrevivência digna do cidadão (RAMOS, 2014).

$\mathrm{Na}$ atual conjuntura, o critério econômico referido na norma legal vem sendo aplicado de forma objetiva na seara administrativa da Previdência Social, ocasionando o indeferimento de inúmeros requerimentos de benefício de prestação continuada, uma vez que não há a ponderação do princípio da dignidade humana. Como consequência imediata de tais indeferimentos está a grande demanda judicial, com a propositura de inúmeras ações visando o reconhecimento da miserabilidade de seus proponentes.

Diante das inúmeras ações judiciais, a jurisprudência passou a evoluir, considerando uma interpretação mais abrangente ao critério econômico utilizado, visando a observância dos princípios constitucionais, vejamos:

BENEFÍCIO ASSISTENCIAL. CONCESSÃO. PORTADOR DE DEFICIÊNCIA. MENOR. CONDIÇÃO SOCIOECONÔMICA. MISERABILIDADE. PREENCHIMENTO DE REQUISITOS. CONSECTÁRIOS LEGAIS. IMPLANTAÇÃO DO BENEFÍCIO. 1. O direito ao benefício assistencial, previsto no art. 203, V, da Constituição Federal, e nos arts. 20 e 21 da Lei 8.742/93 (LOAS) pressupõe o preenchimento de dois requisitos: a) condição de pessoa com deficiência ou idosa e b) situação de risco social, ou seja, de miserabilidade ou de desamparo. 2. Reconhecida a inconstitucionalidade do critério econômico objetivo em regime de repercussão geral, bem como a possibilidade de admissão de outros meios de prova para verificação da hipossuficiência familiar, cabe ao julgador, na análise do caso concreto, aferir o estado de miserabilidade da parte autora e de sua família. 3 . A situação retratada nos autos, onde criança com deficiência auditiva séria se encontra em situação de vulnerabilidade social comprovada, compromete suas chances de efetiva participação social em pé de igualdade na vida social, dadas as barreiras presentes na vida comunitária, ensejando a proteção jurídica prevista no benefício de prestação continuada. Ademais, a proteção jurídica à criança com deficiência vai além da constatação da vulnerabilidade contemporânea, ao atentar para os prejuízos ao desenvolvimento de futuras e potenciais capacidades e chances de inclusão e de exercício de direitos. 4. Preenchidos os requisitos no caso em apreço, é de ser concedido o benefício pleiteado. 5 . A definição dos índices de correção monetária e juros de mora deve ser diferida para a fase 
de cumprimento do julgado. 6 . O cumprimento imediato da tutela específica independe de requerimento expresso do segurado ou beneficiário, e o seu deferimento sustenta-se na eficácia mandamental dos provimentos fundados no art. 461 do CPC/1973, bem como nos artigos 497, 536 e parágrafos e 537 do CPC/2015. 7. A determinação de implantação imediata do benefício, com fundamento nos artigos supracitados, não configura violação dos artigos 128 e 475-O, I, do CPC e 37 da Constituição Federal (BRASIL, 2016b, texto digital, grifo nosso).

BENEFÍCIO ASSISTENCIAL. MENOR. PORTADOR DE DEFICIÊNCIA. CONDIÇÃO SOCIOECONÔMICA. MISERABILIDADE. PREENCHIMENTODE REQUISITOS. RENDA FAMILIAR. ART. 20, §3을 DA LEI 8.742/93. RELATIVIZAÇÃO DO CRITÉRIO ECONÔMICO OBJETIVO. STJ E STF. PRINCÍPIOS DA DIGNIDADE DA PESSOA HUMANA E DO LIVRE CONVENCIMENTO DOJUIZ. CONSECTÁRIOS LEGAIS. TUTELA ESPECÍFICA. IMPLANTAÇÃO DO BENEFÍCIO. 1. O direito ao benefício assistencial previsto no art. 203, V, da Constituição Federal e no art. 20 da Lei 8.742/93 (LOAS) pressupõe o preenchimento de dois requisitos: a) condição de pessoa com deficiência ou idosa e b) condição socioeconômica que indique miserabilidade; ou seja, a falta de meios para prover a própria subsistência ou de tê-la provida por sua família. 2. Não há impedimento à concessão do benefício assistencial de prestação continuada ao menor que demonstre necessitar de amparo. A assistência social a crianças e adolescentes é prioritária no Brasil, à luz do art. 203, incisos I e II, da Constituição Federal, proteção reforçada se o menor é deficiente, conforme disposto pelos incisos IV e V do mesmo artigo. 3. O Superior Tribunal de Justiça, ao julgar o REsp 1.112.557 representativo de controvérsia, relativizou o critério econômico previsto no art. 20, $\S 3^{\circ}$, da Lei $8.742 / 93$, admitindo a aferição da miserabilidade da pessoa deficiente ou idosa por outros meios de prova que não a renda per capita, consagrando os princípios da dignidade da pessoa humana e do livre convencimento do juiz. 4. Reconhecida pelo STF, em regime de repercussão geral, a inconstitucionalidade do $\S^{\circ}$ do art. 20 da Lei 8.742/93 (LOAS), que estabelece critério econômico objetivo, bem como a possibilidade de admissão de outros meios de prova para verificação da hipossuficiência familiar em sede de recursos repetitivos, tenho que cabe ao julgador, na análise do caso concreto, aferir o estado de miserabilidade da parte autora e de sua família, autorizador ou não da concessão do benefício assistencial. 5. Declarada pelo Supremo Tribunal Federal a inconstitucionalidade do art. $1^{\circ}-\mathrm{F}$ da Lei $\mathrm{n}^{\circ} 9.494 / 97$, com a redação dada pela Lei $\mathrm{n}^{\circ}$ 11.960/2009, os juros moratórios devem ser equivalentes aos índices de juros aplicáveis à caderneta de poupança (STJ, REsp 1.270.439/ PR, $1^{\text {a }}$ Seção, Relator Ministro Castro Meira, 26/06/2013). No que 
tange à correção monetária, permanece a aplicação da TR, como estabelecido naquela lei e demais índices oficiais consagrados pela jurisprudência. 6. O cumprimento imediato da tutela específica independe de requerimento expresso do segurado ou beneficiário, e o seu deferimento sustenta-se na eficácia mandamental dos provimentos fundados no art. 461 do CPC/1973, bem como nos artigos 497, 536 e parágrafos e 537 do CPC /2015. 7. A determinação de implantação imediata do benefício, com fundamento nos artigos supracitados, não configura violação dos artigos 128 e 475-O, I, do CPC e 37 da Constituição Federal (BRASIL, 2016a, texto digital, grifo nosso).

Diante da análise das ementas elencadas, verifica-se que no âmbito judicial a norma legal é contraposta ao princípio da dignidade humana, da solidariedade e do não retrocesso, mesmo que não expressamente, levando-se em consideração as condições de vida do requerente e o período socioeconômico que se encontra o cidadão. Assim, o magistrado, ao aplicar os princípios constitucionais, consegue comprovar a situação de miserabilidade do autor da ação, mesmo que este não se enquadre no critério econômico disposto na norma legal. Uma vez comprovado que a renda familiar, mesmo que superior a 1/4 (um quarto) do salário mínimo per capita, não é suficiente para garantir a subsistência digna de cada membro da família, faz-se necessário o auxílio do Estado, o qual tem a obrigação de garantir a aplicação dos princípios fundamentais.

\section{CONCLUSÃO}

O ano de 2017 é anunciado como o ano de reformas legislativas. São reformas previdenciárias, trabalhistas, dentre outras. O caos político e econômico está implantado na sociedade brasileira.

Consequência disso, os menos favorecidos, assalariados ou não, enfrentam grandes dificuldades financeiras, com déficit de empregos, problemas na saúde e educação pública.

A assistência social ainda não foi, especificamente, objeto de debate, no entanto, é necessário ressaltar que, como visto no corpo do trabalho, os direitos, garantias e princípios constitucionais não podem ser suprimidos ou inobservados quando da construção de nova norma legal.

Outro ponto importante diz respeito ao trabalho realizado pelos julgadores, os quais são os operadores do direito que garantem a aplicabilidade das normas anteriormente citadas.

Conclui-se que a interpretação da legislação assistencial deve ser norteada pelos princípios da solidariedade, do não retrocesso e da dignidade humana, a fim de cumprir os preceitos constitucionais da Carta Magna. 
Em que pese haver necessidade de mudanças no cenário das leis, estas devem sempre estar de acordo com normas e princípios tidos como fundamentais, os quais deverão ser invocados a cada discussão na construção jurídica, a fim de evitar um retrocesso social.

\section{REFERÊNCIAS}

BALERA, Wagner; MUSSI, Cristiane Miziara. Série Concursos Públicos - Direito Previdenciário. 11. ed. São Paulo: Método, 2015. E-book. Disponível em: <www. univates.br/biblioteca>. Acesso em: 30 jan. 2017.

BARROSO, Luís Roberto. Curso de direito constitucional contemporâneo: os conceitos fundamentais e a construção do novo modelo. 5. ed. São Paulo: Saraiva, 2014. E-book. Disponível em: <www.univates.br/biblioteca>. Acesso em: 25 fev. 2017.

BRASIL. Constituição (1988). Constituição da República Federativa do Brasil. Disponível em: <http://www.planalto.gov.br/ccivil_03/Constituicao/Constituicao. htm>. Acesso em: 11 set. 2016.

. Lei n ${ }^{\circ} 8.742$, de 7 de dezembro de 1993. Dispõe sobre a organização da Assistência Social e dá outras providências. Disponível em: <http://www.planalto. gov.br/ccivil_03/leis/L8742.htm>. Acesso em: 20 fev. 2017.

. Superior Tribunal de Justiça. Recurso Especial Repetitivo RESP n ${ }^{\circ} 1112557$ / MG. Terceira Seção. Ministro Relator: Napoleão Nunes Maia Filho. Brasília, 20 nov. 2009. Disponível em: <http://www.stj.jus.br/webstj/Processo/Repetitivo/relatorio_ assunto.asp>. Acesso em: 02 fev. 2017.

. Supremo Tribunal Federal. Tribunal Pleno. Reclamação n ${ }^{\circ} 4374 /$ PE. Reclamante: INSS. Reclamado: Turma Recursal dos Juizados Especiais Federais do Estado de Pernambuco. Ministro Relator: Gilmar Mendes. Brasília, 18 abr. 2013. Disponível em: <http://stf.jus.br/portal/jurisprudencia/listarJurisprudencia.asp?s1 = \%28Rcl $\% 24 \% 2 \mathrm{ESCLA} \% 2 \mathrm{E}+\mathrm{E}+4374 \% 2 \mathrm{ENUME} \% 2 \mathrm{E} \% 29+\mathrm{OU}+\% 28 \mathrm{Rcl} \% 2 \mathrm{EA}-$ CMS\%2E+ADJ2+4374\%2EACMS\%2E\%29\&base=baseAcordaos\&url=http://tinyurl. com/awgnwxq>. Acesso em: 23 jun. 2015.

. Tribunal Regional Federal da Quarta Região (Quinta turma). Apelação Cível/Reexame Necessário no 0003372-22.2016.404.9999. Apelante: Henrique Gomes. Apelado: Instituto Nacional do Seguro Social. Relator: Roger Raup Rios. Porto Alegre, 05 jul. 2016a. Disponível em: <http://jurisprudencia.trf4.jus.br/pesquisa/resultado_ pesquisa.php>. Acesso em: 10 out. 2017.

- Tribunal Regional Federal da Quarta Região (quinta turma). Apelação Cível ${ }^{\circ}$ 5003099-38.2015.404.7203. Apelante: Henrique Gomes. Apelado: Instituto Nacional do Seguro Social. Relator: Roger Raup Rios. Porto Alegre, 07 dez. 2016b. Disponível em: <http://jurisprudencia.trf4.jus.br/pesquisa/resultado_pesquisa.php>. Acesso em: 10 jan. 2017. 
Câmara dos Deputados. Projetos de Lei e Outras Proposições: PEC 287/2016. Disponível em: http://www.camara.gov.br/proposicoesWeb/ fichadetramitacao?idProposicao=2119881. Acesso em: 25 fev. 2017.

CANOTILHO, J. J. Gomes. Direito constitucional e teoria da constituição. 7. ed. São Paulo: Saraiva, 2003.

CARDOSO, Alenilton da Silva. Princípio da Solidariedade: o paradigma ético do direito contemporâneo. São Paulo: Juarez de Oliveira, 2010.

CASTRO, Carlos Alberto Pereira de; LAZZARI, João Batista. Manual de direito previdenciário. 16. ed. Rio de Janeiro: Forense, 2014.

CORREIA, Marcus Gonçalves. Curso de direito da seguridade social. 7. ed. Saraiva, 2013. E-book. Disponível em: <www.univates.br/biblioteca>. Acesso em: 18 jul. 2016.

CUNHA, Maria Neusa Fernandes da. A dignidade da pessoa humana e a efetivação da justiça. Âmbito Jurídico, Rio Grande, XV, n. 103, ago., 2012. Disponível em: <http://www.ambito-juridico.com.br/site/?n_link=revista_artigos_leitura\&artigo_ $\mathrm{id}=12111>$. Acesso em: 25 fev. 2017.

FERREIRA, Antônio O. Princípio constitucional do não retrocesso. Ago. 2015.

Disponível em: <http:/ /jota.info/artigos/principio-constitucional-do-naoretrocesso-06082015>. Acesso em: 25 jan. 2017.

FUKUYAMA, Francis. Nosso futuro pós-humano: consequências da revolução da biotecnologia. Rio de Janeiro: Rocco, 2003.

HUBACK, Kerlly. Manual de Direito Previdenciário. 8. ed. São Paulo: Método, 2012. E-book. Disponível em: <www.univates.br/biblioteca>. Acesso em: 30 jan. 2017.

LIMA, George Marmelstein. As funções dos princípios constitucionais. Jus Navegandi, Teresina, ano 7, n. 54, 1 fev. 2002. Disponível em: <http:/ /jus.com.br/ revista/texto/2624>. Acesso em: 25 fev. 2017.

MACIEL, Álvaro dos Santos. Do princípio do não retrocesso social. Boletim Jurídico, Ano XVI, n. 1419, nov., 2008. Disponível em: <http://www.boletimjuridico.com.br/ doutrina/texto.asp?id=1926>. Acesso em: 25 fev. 2017.

RAMOS, André de Carvalho. Curso de direitos humanos. São Paulo: Saraiva, 2014.

SARLET, Ingo; MARINONI, Luiz Guilherme; MITIDIERO, Daniel. Curso de Direito Constitucional. 4. ed. ampl. Incluindo novo capítulo sobre direitos fundamentais. São Paulo: Saraiva, 2015.

SARLET, Ingo Wolfgang. Dignidade da pessoa humana e direitos fundamentais na Constituição Federal de 1988. 9. ed. rev. atual. Porto Alegre: Livraria do Advogado Editora, 2012.

STRECK, Lenio Luiz; MORAIS, José Luiz Bolzan de. Ciência Política e Teoria do Estado. 5. ed. rev. atual. Porto Alegre: Livraria do Advogado, 2006. 